\title{
MODELO DE REGRESSÃO LINEAR PARA ANÁLISE DE INVESTIMENTOS EM UMA EMPRESA DO RAMO PETROLÍFERO
}

\author{
E.V.P. Bastos ${ }^{1 *}$; J. C. F. Guimarães ${ }^{2}$; E. A. Severo ${ }^{2}$ \\ 1 Centro de Instrução Almirante Graça Aranha (CIAGA), 21030-001, Rio de Janeiro-RJ, Brasil \\ 2 Faculdade Meridional (IMED), 99070-220, Passo Fundo-RS, Brasil \\ *bastos.2om@gmail.com
}

Artigo submetido em 01/2015 e aceito em 04/2015

\section{RESUMO}

As mudanças no cenário da economia mundial fizeram com que as empresas, principalmente as de capital aberto, busquem adaptações ao modelo globalizado de mercado, o qual dá preferência à análise dos indicadores de rentabilidade de suas ações. Neste sentido, realizou-se uma pesquisa quantitativa, com base nos dados publicados pela empresa Petrobras S.A., relativos ao balanço patrimonial dos anos de 2009 a 2013. A análise dos dados ocorreu por meio de métodos estatísticos de covariância, correlação e regressão linear. Entre os achados da pesquisa, destaca-se que mais do que comprovar as boas relações entre os bons resultados históricos, os conjuntos de técnicas dos métodos estatísticos servem como alertas para indicar aos gestores que algo não está indo como se esperava, dessa forma, auxiliar na decisão de promover uma mudança nas políticas internas da empresa, mais especificamente nas formas de alocação dos investimentos.

PALAVRAS-CHAVE: Balanço Patrimonial, Análise de Investimentos, Correlação, Regressão Linear, Covariância.

\section{LINEAR REGRESSION MODEL FOR INVESTMENT ANALYSIS OF AN OIL COMPANY}

\begin{abstract}
Changes in global economic environment meant that companies, particularly publicly traded, seek adaptations to global market model, which gives preference to the analysis of stock indicators profitability. In this sense, we carried out a quantitative study, based on data published by Petrobras SA, concerning the balance sheet comprising the period 2009 to 2013. Data analysis was carried out through statistical methods of covariance, correlation and linear regression. Among the findings of
\end{abstract}

the paper, we emphasize that more than prove the good relations between the good historical results, the joint techniques of statistical methods serve as warnings to indicate to managers that something is not going as expected, thus helping the decision to promote a change in internal company policies, specifically in the way of investment allocation.

KEYWORDS: Balance sheet, Investment analysis, Correlation, Linear Regression, Covariance. 


\section{INTRODUÇÃO}

Com as mudanças no cenário da economia mundial as empresas, principalmente as de capital aberto, têm buscado adaptações ao modelo globalizado de mercado que dá preferência à análise dos indicadores de rentabilidade de suas ações.

Segundo Assaf Neto (2009), as organizações têm revelado importantes avanços, por meio da mudança de uma postura convencional, com ênfase no lucro e na rentabilidade, para uma análise voltada à riqueza dos acionistas. Enquanto o lucro permite que as decisões financeiras sejam avaliadas pelo resultado contábil, a rentabilidade avalia com base no resultado econômico, ou seja, considera o custo de oportunidade do capital próprio e o risco do negócio. Sendo assim, a criação da riqueza, baseia-se na diferença entre o valor de mercado da organização e o capital investido pelos proprietários.

Logo, podem-se inserir métodos estatísticos como importantes ferramentas de controle do cenário e, principalmente, na tomada de decisão. Esses conjuntos de métodos são, neste estudo, aplicados aos indicadores de volume financeiro das ações ordinárias, volume financeiro das ações preferenciais, valor de mercado, valor patrimonial, volume de vendas, lucro líquido e investimentos realizados.

Por conseguinte, realizou-se um estudo com os itens mais importantes para o cálculo do balanço patrimonial, mais especificamente com relação ao cálculo dos ativos circulantes. Para essa análise identificou-se os itens de maior impacto nesse tipo de ativo, constituído por: i) caixa e equivalente de caixa; ii) contas a receber; iii) estoques; iv) títulos e valores mobiliários; v) impostos e taxas a recuperar; vi) ativos não correntes para vendas.

O objetivo deste estudo consiste em justificar os investimentos realizados pela empresa Petrobras S.A, com seus respectivos resultados obtidos no período de janeiro de 2009 a dezembro de 2013. Neste sentido, realizou-se uma lógica inversa de raciocínio de forma que fosse possível, através dos resultados quantitativos, analisar o investimento prévio realizado e verificar sua coerência com os resultados.

Por esse motivo, na equação da regressão, os investimentos foram considerados as variáveis dependentes e seus resultados com as respectivas variáveis independentes. Estruturando a análise desta forma é possível observar a discrepância do valor necessário para aquele resultado e o valor real que foi investido.

$\mathrm{Na}$ segunda parte desta pesquisa realizou-se um estudo de correlação e uma aplicação da regressão linear nos itens que compõe o cálculo dos ativos circulantes, com isso pretende-se verificar quais itens têm uma maior contribuição para o aumento desse tipo de ativo, o qual é importante para o cálculo do balanço patrimonial, nesta etapa do artigo foram considerados dados mais recentes disponíveis ao investidor no site da empresa no período de julho de 2013 a junho de 2014.

\section{REVISÃO DE LITERATURA}

\subsection{Balanço patrimonial}

O patrimônio pode ser definido como o conjunto de bens, direitos e obrigações, o qual é demonstrado no balanço patrimonial seguinte forma: i) ativo, onde os bens e direitos são mensuráveis monetariamente, e que representam benefícios presentes ou futuros; ii) passivo, o qual apresenta as obrigações que serão exigidas por terceiros, complementadas pelos recursos investidos 
pelos proprietários deste patrimônio, ou acumulados pelo processo de gestão deste patrimônio, sendo estes recursos denominados de patrimônio líquido (MARON, 2005).

O balanço patrimonial consiste na demonstração, em determinada data, normalmente este é anual, da situação financeira e patrimonial de um empreendimento, o qual apresenta, entre outras informações, o passivo e o patrimônio líquido (IUDÍCIBUS et al., 2007; HIRASHIMA, 2006). O passivo é constituição das exigibilidades da empresa, os quais são os valores que a empresa tem a obrigação de pagar a terceiros no momento da avaliação. Enquanto que o patrimônio líquido é a diferença entre o ativo e o passivo de uma organização, constituído pelos recursos que os proprietários investiram no empreendimento e os lucros gerados pela operação (HIRASHIMA, 2006; IUDÍCIBUS; MARION, 2006). As informações contábeis formam a contabilidade gerencial, a quais são essenciais à gestão dos negócios e à sobrevivência das organizações (CAMIN et al., 2014).

\subsection{Covariância}

A covariância é uma medida de associação linear entre as variáveis aleatórias. Se a relação entre as variáveis aleatórias for não linear, a covariância pode não ser sensível à relação (MONTGOMERY, 2011).

A covariância entre as variáveis aleatórias $\mathrm{X}$ e $\mathrm{Y}$, denotada por $\sigma_{X Y}$ é:

$$
\sigma_{X Y}=E\left[\left(X-\mu_{X}\right)\left(Y-\mu_{Y}\right)\right]=E(X, Y)-\mu_{X} \mu_{Y}
$$

\subsection{Correlação}

A correlação só escalona a covariância através do desvio-padrão de cada variável. Assim, a correlação é uma quantidade adimensional que pode ser usada para comparar as relações lineares entre pares de variáveis em diferentes unidades. (MONTGOMERY, 2011).

A correlação entre as variáveis aleatórias X e Y, denotada pelo coeficiente de correlação $\rho_{X Y}$, é representado matematicamente como:

$$
\rho_{\mathrm{XY}}=\frac{\operatorname{cov}(\mathrm{X}, \mathrm{Y})}{\sqrt{\mathrm{V}(\mathrm{X}) \mathrm{V}(\mathrm{Y})}}=\frac{\sigma_{\mathrm{XY}}}{\sigma_{\mathrm{X}} \sigma_{\mathrm{Y}}}
$$

\subsection{Regressão Linear}

$\mathrm{O}$ caso de regressão linear simples considera um único regressor ou preditor $\mathrm{x}$ e uma variável dependente ou variável de resposta Y. Suponha que a relação verdadeira entre Y e x seja uma linha reta e que observação em cada nível de x seja uma variável aleatória. Como notado previamente, o valor esperado de Y para cada valor de x é:

$$
E(Y \mid x)=\beta_{0}+\beta_{1} x
$$

Sendo a interseção $\beta_{0}$ e a inclinação $\beta_{1}$ coeficientes desconhecidos a serem calculados na equação da regressão. Consideramos que cada observação, Y, possa ser descrita pelo modelo:

$$
Y=\beta_{0}+\beta_{1} x+\epsilon
$$

Em que $\epsilon$ é um erro aleatório com média zero e variância $\sigma^{2}$. Os erros aleatórios correspondendo a diferentes observações são também considerados variáveis aleatórias não correlacionadas.

Já na Regressão linear múltipla têm-se um modelo de regressão que envolve mais de uma variável regressora. Dessa forma tem-se:

$$
Y=\beta_{0}+\beta_{1} x 1+\beta_{2} x 2+\cdots+\beta_{n} x n+\epsilon .
$$


Esse modelo de regressão linear múltipla é utilizado como uma função aproximadora, ou seja, a verdadeira relação entre $\mathrm{Y}$ e $X_{1}, X_{2} \ldots X_{N}$ é desconhecida, porém, dentro de certos limites das variáveis independentes, o modelo de regressão linear é uma aproximação adequada. $O$ coeficiente de determinação $\mathrm{R}^{2}$ indica a força da relação, mais especificamente $\mathrm{o} \mathrm{R}^{2}$ explica que um percentual de variação da variável dependente é justificado pela variável independente, ou seja, é a quantidade da variabilidade nos dados explicada pela equação da regressão obtida, (MONTGOMERY, 2011).

\section{METODOLOGIA}

De acordo com Selltiz (1975), as pesquisas se classificam em três grupos, sendo elas: exploratórias, descritivas e causais. Os estudos exploratórios têm como objetivo a descoberta de ideias e intuições. Os descritivos apresentam características de uma situação, grupo ou indivíduo específico. Os causais, por sua vez, são aqueles que verificam uma hipótese de relação causal entre variáveis.

Neste cenário, os objetivos desta pesquisa estão de acordo com a definição de pesquisa causal, pois este estudo busca verificar uma relação de causa entre as variáveis abordadas. A metodologia adotada para esta pesquisa é o estudo de caso único, a qual Yin (2005) define como uma investigação empírica, que visa estudar um fenômeno contemporâneo inserido em um contexto, especialmente quando os limites entre o fenômeno e o contexto não estão claramente definidos. Esta pesquisa ocorreu na empresa Petrobrás S.A. com abordagem quantitativa por meio da aplicação dos métodos estatísticos como correlação, coeficiente de determinação, regressão e gráficos comparativos.

A coleta de dados e de informações ocorreu por meio de análise documental, no site da Petrobras S. A., pois se trata da técnica que melhor se adaptou ao contexto metodológico da pesquisa (MALHOTRA et al., 2005). Para o levantamento dos dados, foram utilizados os relatórios anuais, que estão divulgados no site institucional da empresa, mais especificamente foram utilizados os relatórios de atividades, relatório da administração e panorama anual.

\section{RESULTADOS E DISCUSSÕES}

\subsection{Análise dos investimentos realizados}

Inicialmente foram aplicados os conceitos de correlação e regressão linear simples entre o montante de investimentos realizados e as outras cinco variáveis relacionadas.

Os investimentos realizados fazem parte do conjunto de estratégias corporativas que visam à expansão dos negócios da companhia, baseados nos conceitos de sustentabilidade, crescimento integrado, rentabilidade, responsabilidade social e ambiental, esse programa de investimentos é realizado no Brasil e no exterior. Os setores que concentram esses investimentos são o de exploração e produção, que atualmente leva a maior parte desses recursos, o segmento de refino, transporte e comercialização em segundo lugar no montante dos investimentos, seguidos pelos setores de gás-energia, gás-química, bicombustíveis, internacional e corporativo.

\subsubsection{Investimentos e valor de mercado}

Valor de mercado é o valor das empresas que possuem capital aberto, ou seja, tem papéis negociados na bolsa de valores, seu cálculo é realizado pela multiplicação da quantidade de cada tipo ou classe de ação emitida pela empresa pela sua cotação atual no mercado, o preço pelo qual os papeis estão sendo negociados. 
O valor obtido para a correlação entre os investimentos realizados e o valor de mercado foi de $-0,79$, considerado um alto coeficiente negativo, indicando que no período analisado, as duas variáveis caminharam em sentidos opostos.

Já na analise da regressão linear simples entre essas duas variáveis obtemos a seguinte equação: $Y=-0,16 X+129964$.

Onde $\mathrm{Y}$ representa os investimentos realizados e $\mathrm{X}$ o valor de mercado.

O coeficiente angular negativo na equação da regressão acima comprova a relação inversa indicada pela correlação negativa. Além disso, foi obtido um coeficiente $\mathrm{R}^{2}$ igual a 0,63 indicando que $63 \%$ da variável dependente investimentos pode ser explicada pela variável independente valor de mercado.

Graficamente pode-se visualizar a reta da regressão na Figura 1.

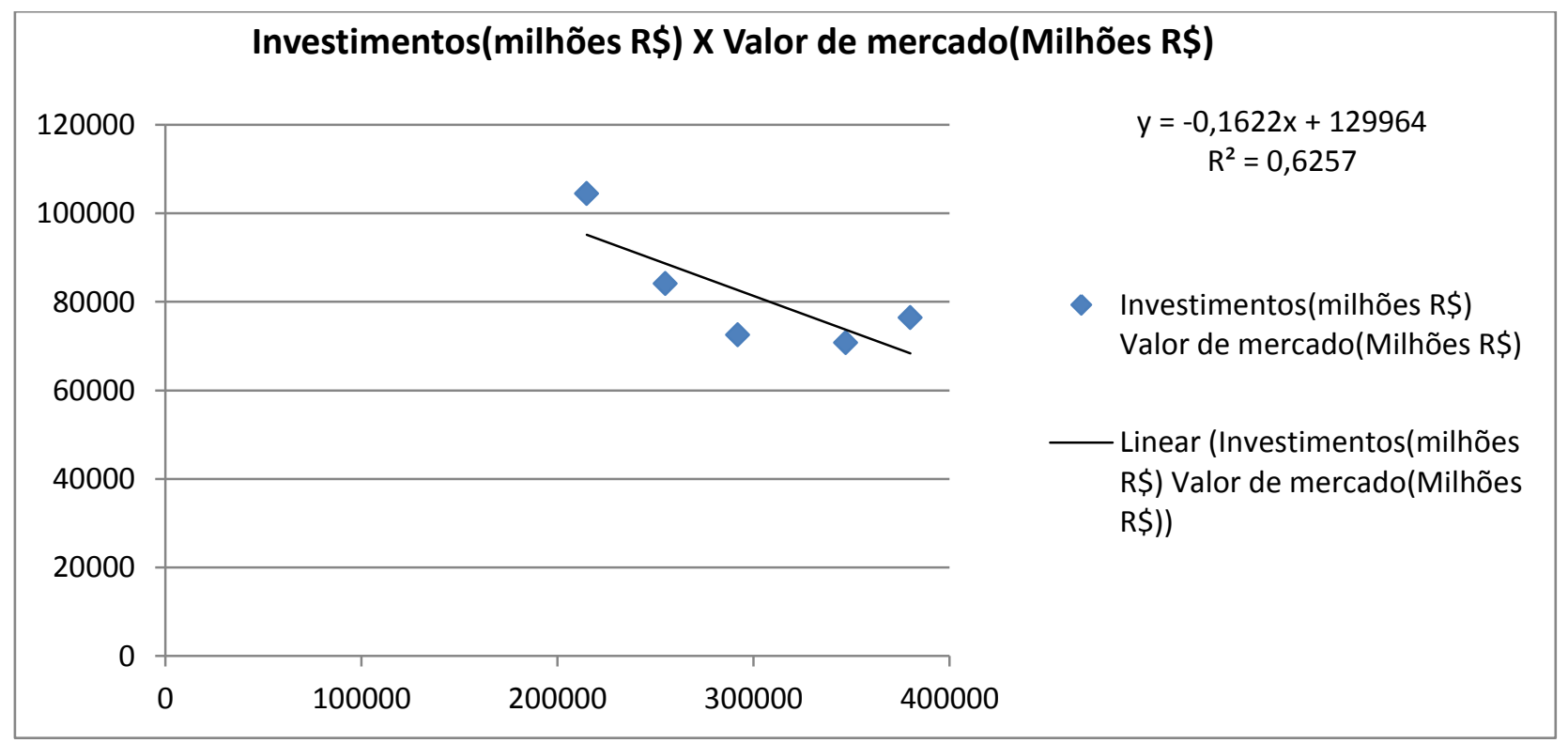

Figura 1 - Regressão de investimento versus valor de mercado

Fonte: Dados da pesquisa (2015)

\subsubsection{Investimentos e Valor patrimonial}

Valor patrimonial é o valor total dos bens de uma empresa sem levar em consideração suas ações e possíveis potenciais de geração de resultados. Resumidamente, pode-se dizer que é o valor contábil registrado no balanço patrimonial.

Para a correlação entre os investimentos e o valor patrimonial da empresa Petrobrás, no período analisado, foi encontrado o valor 0,57 considerado um positivo e moderado coeficiente de correlação indicando que as variáveis moveram-se no mesmo sentido durante esse período.

Já na análise da regressão linear simples entre as duas variáveis acima, obtemos um coeficiente $\mathrm{R}^{2}$ igual a 0,32 indicando que cerca de $32 \%$ das variações na variável investimentos ocorrem por influência do valor patrimonial.

A equação da regressão pode ser verificada no gráfico da Figura 2. 


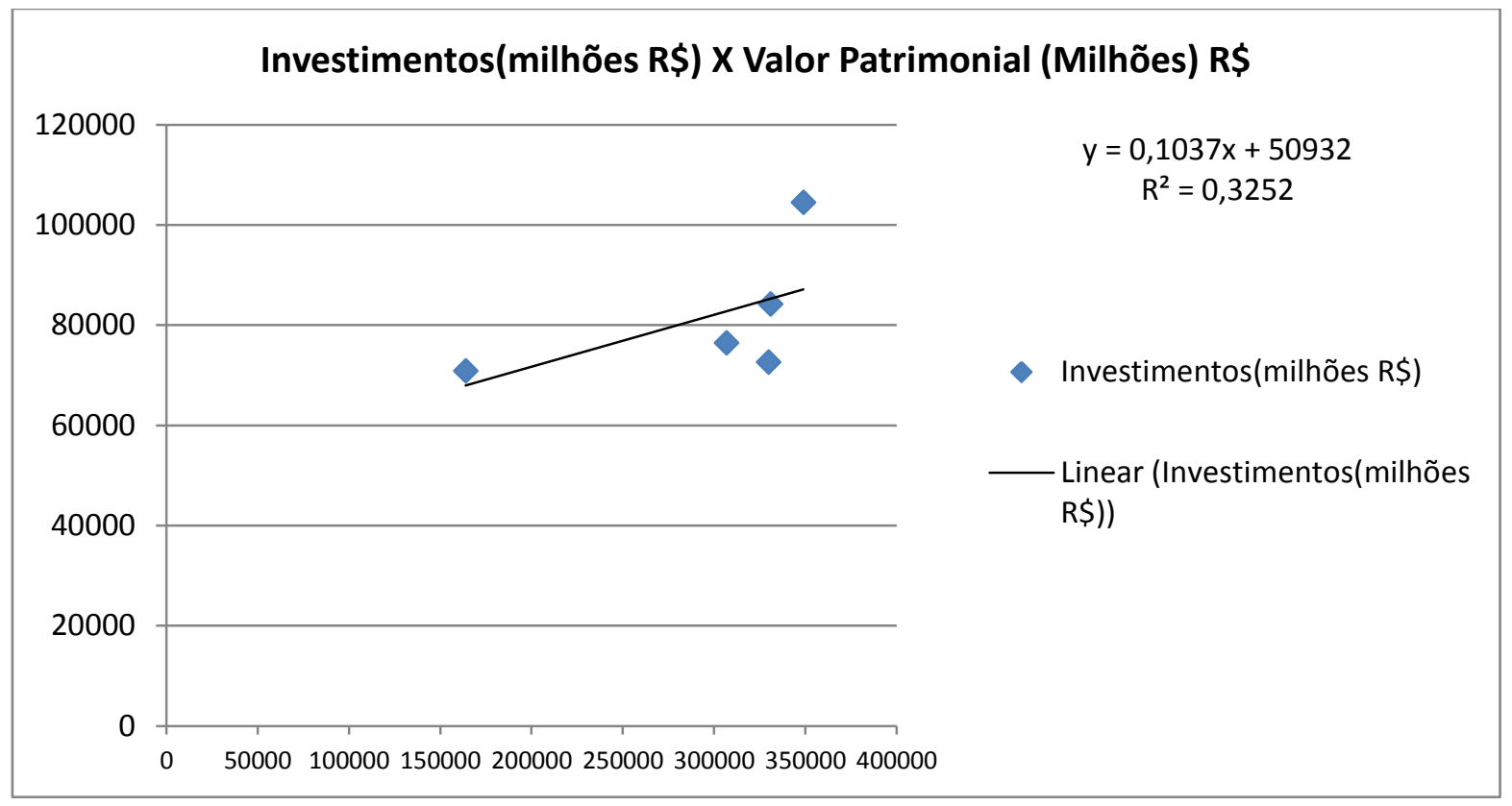

Figura 2 - Regressão de investimento versus valor de patrimonial

Fonte: Dados da pesquisa (2015)

\subsubsection{Investimentos e volume financeiro PETR3}

Volume financeiro das ações, tanto ordinárias quanto preferenciais, é o volume em milhões de reais, negociados na bolsa de valores e mercado futuro BM\&F Bovespa, considerando a média diária, no período estudado. É possível observar que as ações do tipo preferencial tem uma média diária de volume financeiro bem acima das ações ordinárias, isso se deve ao fato de que por possuírem melhor liquidez, os acionistas preferem esse tipo de ação para realizar investimentos do tipo day trade ou até mesmo um swing trade que são os investimentos realizados em um mesmo dia ou posições montadas por alguns dias, respectivamente.

$\mathrm{Na}$ análise entre os investimentos e volume financeiro das ações do tipo PETR3 foi obtido um coeficiente de correlação positivo igual a 0,66 , indicando uma boa relação linear entre essas duas variáveis que no período analisado moveram-se no mesmo sentido.

$\mathrm{Na}$ análise da regressão linear simples foi encontrado um valor de $\mathrm{R}^{2}$ igual a 0,43 indicando que aproximadamente $43 \%$ das variações ocorridas na variável investimentos, se justifica pelo volume financeiro das ações PETR3.

No gráfico da Figura 3 pode-se verificar a equação da regressão encontrada. 


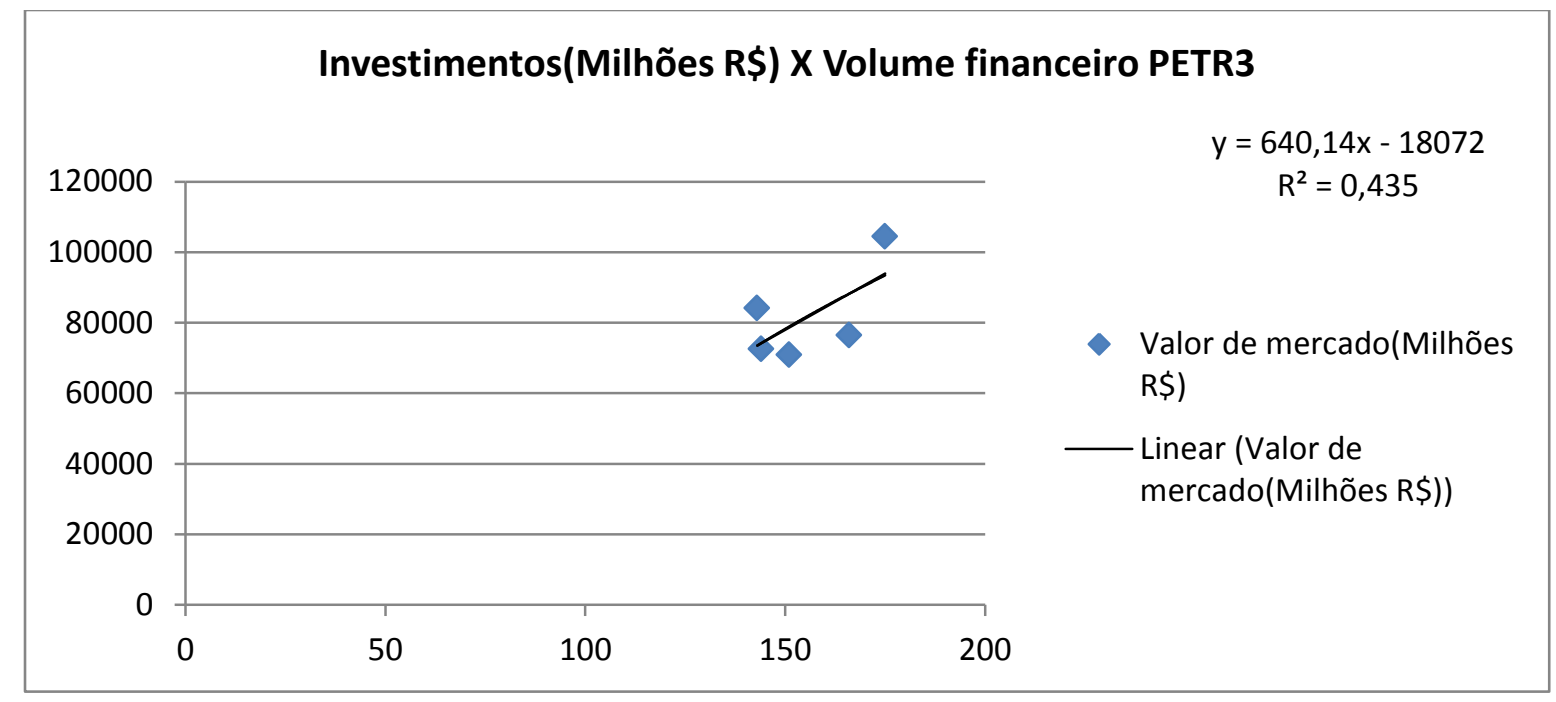

Figura 3 - Regressão de investimento versus volume financeiro

Fonte: Dados da pesquisa (2015)

\subsubsection{Investimentos e volume de vendas}

Volume de vendas, considerado neste estudo, é o volume vendido pelo setor de distribuição da Petrobrás que atualmente é a maior distribuidora de combustíveis e seus derivados no Brasil. O valor considerado para aplicação dos métodos estatísticos neste artigo foi em milhões de metros cúbicos vendidos anualmente, no período considerado entre 2013 e 2009.

O valor obtido para a correlação entre o volume de vendas e os investimentos realizados foi de 0,81. O que indica uma alta relação linear entre essas duas variáveis o que já era de certa forma esperado, pois os investimentos devem contribuir para um acréscimo no montante de vendas. A equação da regressão apresentou um bom $\mathrm{R}^{2}$ igual a 0,65 indicando que cerca de $65 \%$ dos valores da variável investimento pode ser explicado pelo volume de vendas. A figura 4 apresenta-se o gráfico com a equação da regressão encontrada.

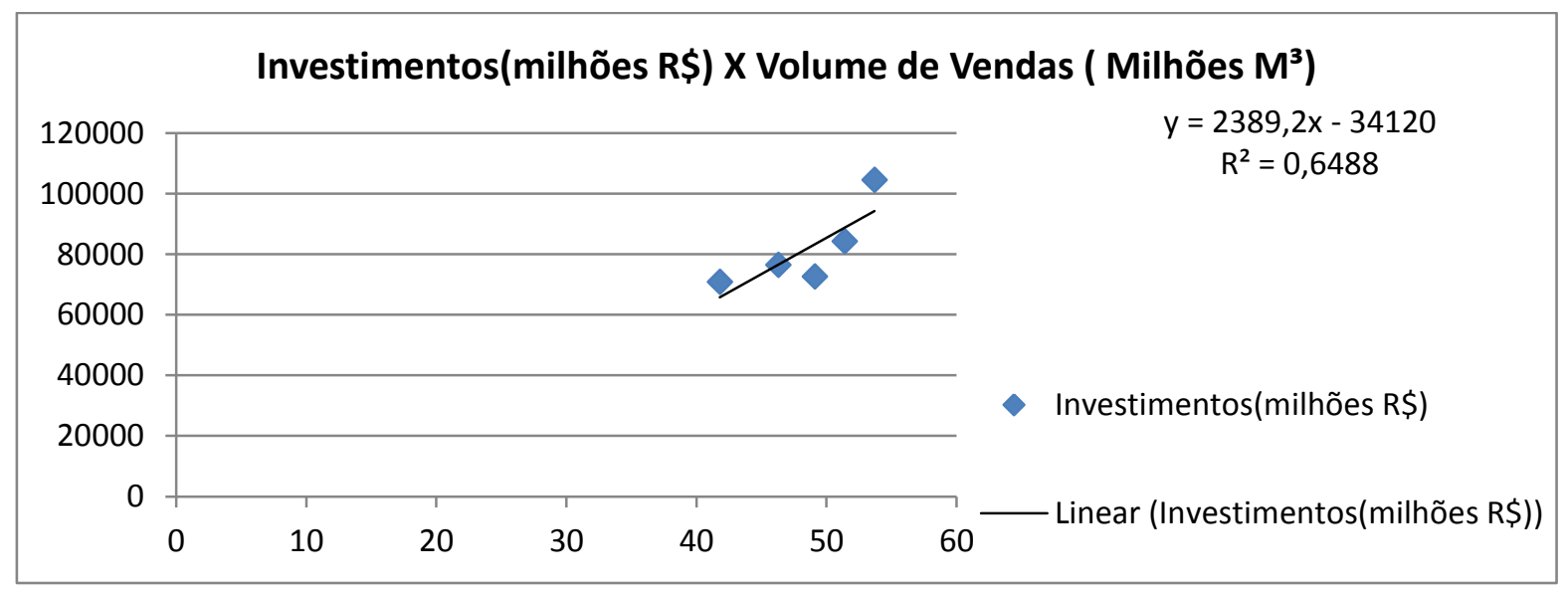

Figura 4 - Regressão de investimento versus volume de vendas

Fonte: Dados da pesquisa (2015) 


\subsubsection{Investimentos e lucro líquido}

Lucro líquido, como o próprio nome define, é o lucro obtido através do faturamento descontando-se todas as despesas impostos e encargos. Ou seja, é o rendimento concreto, o proveito que se pode obter.

Já na análise das variáveis investimento e lucro liquido encontrou-se um coeficiente de correlação negativo igual a -0,68 indicando uma alta relação linear inversa entre as duas variáveis em estudo. A equação da regressão apresentou coeficiente angular negativo o que confirma essa relação inversa. A Figura 5 apresenta o gráfico com a respectiva equação da regressão e seu valor encontrado para $\mathrm{R}^{2}$ igual a 0,46 .

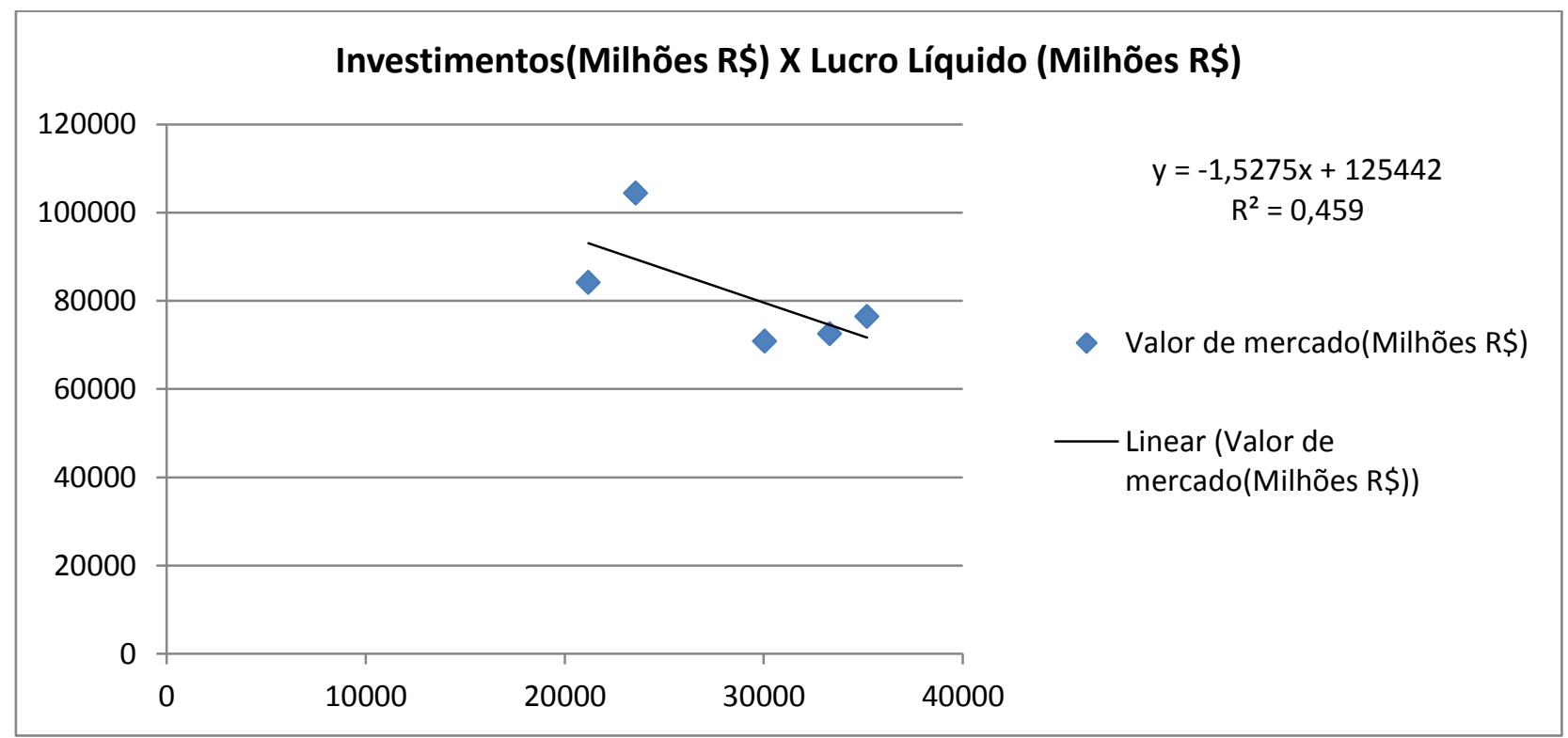

Figura 5 - Regressão de investimento versus lucro líquido

Fonte: Dados da pesquisa (2015)

\subsection{Regressão linear múltipla para análise do valor de mercado e valor patrimonial com os} investimentos realizados

Tendo em vista que os investimentos devem ser justificados, principalmente, pelo valor de mercado e pelo valor patrimonial, considerou-se importante incluir neste artigo um estudo detalhado da regressão linear múltipla entre essas variáveis.

Neste modelo, obteve-se um coeficiente $\mathrm{R}^{2}$ igual a 0,64 indicando que aproximadamente $64 \%$ da variação dos investimentos ocorrem por conta das variáveis valor patrimonial e valor de mercado. Abaixo será apresentada a equação da regressão linear múltipla com seus respectivos coeficientes.

$\mathrm{Y}=0,03 X_{1}-0,14 X_{2}+114875,80 ;$ onde:

$\mathrm{Y}=$ Investimentos;

$X_{1}=\mathrm{o}$ valor patrimonial; e

$X_{2}=0$ valor de mercado. 


\subsection{Análise dos fatores do balanço patrimonial}

$\mathrm{O}$ ativo circulante basicamente compreende em um conjunto de contas do balanço patrimonial, são bens e direitos que podem ser convertidos em espécie no curto prazo, ou seja, ao final de cada exercício social posterior da confecção do balanço patrimonial. São considerados ativos circulantes: caixa e equivalência de caixa, contas a receber, estoques, títulos e valores mobiliários, ativos não correntes para venda, impostos e taxas a recuperar. A seguir será realizada uma descrição mais detalhadas dos conceitos que compõe o cálculo dos ativos circulantes.

Caixa e equivalente de caixa são os valores recebidos em espécie, cheques recebidos em mãos e não depositados pagáveis imediatamente e sem restrição também compreendem caixa. Já as aplicações financeiras de curto prazo, que possuem alta liquidez e que mantidas com o objetivo de suprir demandas de caixa em curto prazo e que não compreendem investimentos ou outros fins, são denominadas equivalência de caixa. Sendo assim, um investimento equivalente de caixa deve atender três requisitos: ser de curto prazo, aqui considerado como no máximo até 90 dias, ter alta liquidez e apresentar baixíssimo risco.

Contas a receber são receitas financeiras que a empresa tem a receber de pessoas físicas ou jurídicas. São decorrentes de vendas realizadas a prazo, de serviços ou mercadorias, sendo assim são oriundos de transações inerentes às atividades da empresa.

Os estoques representam um dos ativos mais importantes da companhia, é considerado um pulmão pela teoria das restrições, pois fornece um fôlego ao cumprimento da demanda quando a mesma está em alta, deve ter sua correta determinação no início e no fim do período contábil, necessário para apuração do lucro líquido do exercício. Os valores em estoques aqui considerados estão representados basicamente por: produtos, mercadorias para revenda, produtos em elaboração e matérias-primas.

Títulos e valores mobiliários são títulos de crédito, registrados e emitidos por entidades públicas ou privadas. Representam direitos e deveres aos titulares podendo ser comprados e vendidos nos mercados de valores mobiliários. Os valores mobiliários representam uma forma de financiamento alternativa, para quem os emitem enquanto que, para os investidores, é uma forma de aplicação de poupança, que se caracteriza por apresentar variedade de risco e potencial de rentabilidade.

Os documentos que representam valores mobiliários podem ser títulos em papel (valores mobiliários titulados) ou registros informáticos (valores mobiliários escriturais). A grande maioria dos valores mobiliários é representada pelo grupo dos valores escriturais por ter facilidade de circulação e transação, pois assim proporcionam maior segurança. Alguns títulos de valores mobiliários e títulos privados de renda fixa são os Certificados de Depósito Bancário (CDB), Letras de Câmbio (LC), Letras Hipotecárias, Certificados de Depósito Interbancário (CDI), Debêntures e Letras Financeiras. Os principais títulos públicos federais são as Letras do Tesouro Nacional (LTN), Letra Financeira do Tesouro (LFT), Nota do Tesouro Nacional (NTN), Notas do Banco Central (NBC).

Impostos e taxas a recuperar é considerado apenas o imposto pago na aquisição de bens, atrelado ao preço, que poderá ser deduzido do tributo devido sobre as vendas de produtos ou prestação de serviços, como é o caso do PIS/COFINS e ICMS.

Ativo não corrente para venda é assim denominado, se for possível recuperar o valor contábil por meio de transação de venda em vez do uso contínuo. Os Ativos mantidos para essa finalidade devem estar disponíveis para venda imediata em suas condições atuais, sujeito apenas aos termos que sejam habituais. Assim, deve haver a real possibilidade de venda. $\mathrm{O}$ ativo não corrente 
para venda deve ser colocado à venda a preço que seja razoável quando comparado ao seu valor justo de mercado.

A Tabela 1 destaca os principais fatores levados em consideração para o cálculo dos ativos circulantes e suas respectivas correlações com o mesmo.

Tabela 1 - Principais fatores para o cálculo dos ativos circulantes

\begin{tabular}{|c|c|}
\hline $\begin{array}{c}\text { Componentes dos ativos } \\
\text { circulantes }\end{array}$ & Correlação \\
\hline Caixa e equivalentes de caixa & 0,93 \\
\hline Contas a receber & 0,66 \\
\hline Estoques & 0,56 \\
\hline Títulos e valores mobiliários & $-0,1$ \\
\hline Impostos e taxas a recuperar & $-0,2$ \\
\hline Ativos não-correntes para venda & $-0,09$ \\
\hline
\end{tabular}

Fonte: Dados da pesquisa (2015).

Dentre os 6 itens analisados no período de julho de 2013 a junho de 2014, para cálculo dos ativos circulantes, que fazem parte do balanço patrimonial da empresa, destaca-se alta correlação linear positiva para caixa e equivalentes de caixa e para o somatório de contas a receber, indicando assim ao gestor quais fatores mais impactam positivamente o valor dos ativos circulantes e consequentemente onde agir corretivamente, caso queira diminuir ou aumentar o valor desses ativos no balanço patrimonial.

Levando-se em consideração o alto valor encontrado na correlação dos itens mencionados acima, foi realizado um estudo de regressão linear múltipla, com o objetivo de obter a equação da relação linear da variável dependente $(Y)$ Ativos circulantes, com as variáveis independentes $\left(X_{i}\right)$ representadas pelo valor caixa e equivalente de caixa e contas a receber.

Foi realizada uma análise do valor encontrado para o coeficiente de determinação $\mathrm{R}^{2}$ da regressão múltipla, igual a 0,98 . Um alto coeficiente indicando que aproximadamente $98 \%$ da variação da variável dependente $\mathrm{Y}$ (Ativos circulantes) é explicado pelas variáveis regressoras caixa equivalentes de caixa e contas a receber. Abaixo segue a equação da regressão linear múltipla obtida.

Foi realizada uma análise do valor encontrado para o coeficiente de determinação $R^{2}$ da regressão múltipla, igual a 0,98 .

Um alto coeficiente indicando que aproximadamente $98 \%$ da variação da variável dependente Y (Ativos circulantes) é explicado pelas variáveis regressoras caixa equivalentes de caixa e contas a receber. A equação da regressão linear múltipla obtida é $\mathrm{Y}=1,53 X_{1}-9,49 X_{1}+$ 280813,8; onde: $\mathrm{Y}=$ Ativo circulante; $X_{1}=$ Caixa e equivalentes de caixa; e $X_{2}=$ Contas a receber.

O teste $f$ foi realizado e conduziu à validação do modelo, assim como os testes $t$ dos regressores individuais validaram cada um dos regressores. 


\section{CONSIDERAÇÕES FINAIS}

$\mathrm{Na}$ análise da correlação de cada variável com o montante de investimentos, destacou-se o volume de vendas com uma alta correlação $(0,80)$ indicando uma boa tendência linear positiva, o que comprova o resultado esperado, uma vez que se aumentando o valor investido objetiva-se atingir volumes maiores de vendas e consequentemente maiores lucros.

Em contrapartida, o valor para a correlação entre o lucro liquido e investimentos, apresentou alta correlação negativa $(-0,68)$, contrariando o que era esperado e, mais importante ainda, servindo como um alerta na medida que alguma política da empresa está desperdiçando os ganhos, tendo em vista os valores crescentes de investimentos paralelamente com os valores crescentes no volume de vendas e mesmo assim a empresa percebe sua margem de lucro diminuir, mostrando uma incoerência na relação investimento/lucro, a qual pode ser estatisticamente verificada. A análise revela informações, com resultados ainda piores ao comparar com o valor obtido da correlação entre investimentos e valor de mercado $(-0,79)$.

O montante de investimentos deve estar relacionado positivamente com o valor de mercado, em uma gestão adequada, ao contrário do que foi verificado no período pesquisado, que percebe-se mais uma evidência estatística sobre a errônea alocação dos recursos destinados ao investimento e crescimento da companhia. Logo, observa-se que parte do montante alocado nas formas de investimento não gerou os resultados que eram esperados para a organização, fato que está em evidência nos noticiários.

Ao analisar a relação entre os investimentos, valor de mercado e valor patrimonial por meio da aplicação da regressão linear múltipla, esperava-se um maior coeficiente $\mathrm{R}^{2}$ tendo em vista que teoricamente, os investimentos, quando realizados de forma correta, agregam inevitavelmente valor à companhia e, como consequência, tem-se um aumento no valor de mercado e no valor patrimonial. Esse estudo mostrou uma tendência inversa, servindo como um alerta para que sejam revistas às aplicações feitas com os recursos disponíveis de investimento da empresa.

Ao observar o valor do coeficiente da variável valor de mercado na equação da regressão linear múltipla exposta anteriormente igual a - 0,14 ,um coeficiente negativo onde era esperado um bom coeficiente positivo. Além disso, o coeficiente da variável valor patrimonial foi considerado muito pequeno $(0,03)$ colaborando assim para que seja feita uma revisão nas formas de investimento da companhia.

Mais do que comprovar as boas relações entre os bons resultados históricos, os conjuntos de técnicas dos métodos estatísticos servem como alertas para indicar aos gestores que algo não está indo como era esperado e, dessa forma auxiliar na decisão de promover uma mudança nas políticas internas da empresa, mais especificamente nas formas de alocação dos investimentos.

$\mathrm{Na}$ análise dos ativos circulantes, item importante no cálculo do balanço patrimonial da Petrobrás, foi encontrado alto coeficiente de correlação linear entre esse item e caixa e equivalentes de caixa e contas a receber. A partir desse indicador foi realizado uma análise mais detalhada por meio da aplicação da regressão linear múltipla nesses três itens. O modelo de regressão apresentou alto coeficiente de determinação $\mathrm{R}^{2}$, sendo assim há um resultado concreto que pode auxiliar aos gestores no momento da tomada de decisão sobre minimizar ou, se desejável, maximizar os ativos circulantes da empresa.

Este estudo apresenta limitações de generalização dos resultados em virtude de tratar-se de um estudo de caso único, entretanto este método de análise pode ser aplicado a outras organizações, independente do setor de atividade. Como acréscimo, sugere-se novos estudos considerando a 
interação de outras variáveis, entre estas investigar o valor pago aos acionistas, na forma de dividendos, com os valores obtidos no volume de vendas e no lucro líquido.

\section{REFERÊNCIAS}

ASSAF NETO, A. Finanças Corporativas e Valor. São Paulo: Atlas, 2003.

CAMIN, C. R.; MARCIANO, V. C.; PASSOS, I. C.; BRITO, E.; GAIO, L. E. Análise crítica da contabilidade gerencial sob a ótica do profissional contábil: um estudo nas empresas atuantes no ramo sucroalcooleiro do interior do estado de São Paulo. Revista de Gestão, Finanças e Contabilidade, v. 4, n. 3, p. 45-63, 2014.

HIRASHIMA, T. (org.) Guia para pesquisas de práticas contábeis: incluindo aspectos tributários relevantes. São Paulo: Atlas, 2006.

IUDICÍBUS, S.; MARION, J. C. Introdução à teoria da contabilidade. 4 ed. São Paulo: Atlas, 2006.

IUDÍCIBUS, S. de et al. Manual de contabilidade das sociedades por ações. 7 ed. São Paulo: Atlas, 2007.

MARION, J. C. Contabilidade empresarial. 11 ed. São Paulo: Atlas, 2005

MALHOTRA, N. K.; ROCHA, I.; LAUDISIO, M. C.; ALTHEMAN, É.; BORGES, F. M. Introdução à pesquisa de marketing. São Paulo: Prentice Hall, 2005.

MONTGOMERY,WILLIAN. Probabilidade e estatística na Engenharia. 4 ed. São Paulo: LTC, 2012.

PETROBRÁS. Óleo Brasileiro S/A - Centro de Negócios. Disponível em: 〈https://www.petrobras.com.br〉. Acesso em 06 de setembro de 2014.

SELltiZ, C. et al. Métodos de Pesquisa nas Relações Sociais. 6 ed. Reimpressão EPU. São Paulo: Editora USP, 1975.

YIN, R. K. Estudo de caso: planejamento e métodos. 3 ed. Porto Alegre: Bookman, 2005 